\title{
Commentary
}

\section{Using Activity-based Genre Theory as a Framework for Analyzing Fund-raising Discourse}

Editor's note: This commentary reflects on papers published in Volume 3, Number 2 of this journal, in October 2002. The theme of the papers was cross-cultural fund raising. Graham Smart is Assistant Professor in the Professional Writing Program in the Department of English at the University of Wisconsin-Milwaukee.

The overarching conclusion to be taken from the five case studies of advancement included in Volume 3, number 2 of the CASE International Journal of Educational Advancement is that each organization must be viewed as a unique entity functioning in a distinctive context of social, historical, cultural, political, and technological influences. In this vein, Professor Ulla Connor ("Epilogue: Case Studies in Cross-cultural Fund Raising," pp. 173-6) points to the value of genre theory for examining the particular homegrown discourse practices used by organizations in their advancement work. Professor Connor also suggests the need for a tertium comparationis-a common frame of reference-for researching the activities and discourses of organizations operating in different countries and cultures. In what follows, I propose one such frame of reference: that of activitybased genre theory.

The field of contemporary rhetoric has recast genre as a form of socio-rhetorical action that, within professional organizations, plays a central role in accomplishing collaborative work. ${ }^{1}$ From this perspective, a written genre can be viewed as a distinctive profile of regularities across four dimensions: a set of texts, the composing processes used to create these texts, the reading practices used to interpret them, and the social interactions of writers and readers. ${ }^{2}$ While these regularities make genres essential sites of stability for organizing the cognition and rhetorical acts of various individuals, genres also exhibit plasticity and a potential for continuous self-transformation. Further, as Professor Connor points out, genre theorists recognize that the genres used within organizations typically function in sets, with each set operating both as a provisionally stable medium for coordinating the intellectual and rhetorical work of a variety of practitioners and as a potential vehicle for organizational change. ${ }^{3}$

To complement this social view of genre, rhetoricians examining discourse in organizations have drawn on North American, British, and Scandinavian extensions of Soviet cultural-historical 
theory known, collectively, as activity theory. From this sociocognitive perspective, a genre set can be viewed as one part of an "activity system": a local sphere of collaborative goal-oriented endeavor, in which thinking, knowing, and learning are distributed across a group of practitioners and their work practices and, at the same time, mediated by an array of culturally constructed tools. ${ }^{4}$ Such culturally constructed tools-which can include, for example, digital technologies, built environments, organizational structures, conceptual frameworks, and genres of written discourse-exert a significant mediating influence on practitioners' thinking, language use, and actions. An aspect of activity systems particularly relevant here is their historical-cultural situatedness, so that in examining an activity system and its genre set we need to attend to the ways in which they have been shaped by distinctive historical and cultural influences.

But how can this theoretical perspective contribute to our understanding of how different organizations use written discourse in their advancement work? I would argue that viewing an organization's discourse as a genre set enmeshed in an organizational activity system-in effect employing the conceptual frame of activity-based genre theory as the kind of tertium comparationis envisioned by Professor Connor-can allow us both to profile organizations as unique entities and to compare a range of organizations for similarities and differences, while at the same time remaining alert to current or imminent changes in organizations and/or their environments.

Next I want to apply the lens of activity-based genre theory to the advancement work of the five organizations described in the case studies. When we look across these organizations, we see the following elements: a range of bistorical/cultural influences, such as those of national, professional, and metaorganizational cultures; the mission or larger goals of advancement, with the particular focus varying somewhat from one organization to another; various advancement practices such as promotion, new-member enrollment, image enhancement, and fund raising; and culturally constructed tools, including organizational structures, conceptual frameworks such as strategic approaches to fund raising, technologies such as electronic databases and websites, and genres such as grant proposals, brochures, flyers, direct-mail letters, case statements, advertisements, subscription lists, and web pages, with their respective composing processes, reading practices, and social interactions.

To conclude, I want to propose a set of questions which could serve both researchers and practitioners as a heuristic for exploring an individual organization's advancement-related discourse or for comparing a number of different organizations.

- What key cultural factors have influenced the organization's advancement activities over its history?

- Which of the following practices define the organization's advancement work: promotion, new-member enrollment, fundraising, image enhancement, political lobbying? Does the organization engage in other advancement practices? How significant a role does each of the practices used by the organization play in its advancement efforts? 
- Which of the following culturally constructed tools play a significant role in mediating the organization's advancement-related thinking and discourse: organizational structure; conceptual frameworks, such as a strategic approach to fund raising, with its constituent tactics; and digital technologies, such as an organizational website or an electronic database? Are there other noteworthy tools in use?

- What constitutes the set of written genres used by the organization in its advancement practices? And for each individual genre, what functions does the genre serve, what kinds of persuasive appeals are deployed, what composing processes are used to produce texts, what reading practices are used to interpret these texts, and what types of social interactions do the texts require and/or facilitate?

- What changes are occurring, or are appearing on the horizon, for the organization's advancement work and related discourse practices?

I would hope that activity-based genre theory, along with the heuristic outlined above, might provide some useful conceptual grounding for international comparative research of organizational advancement work and its discourses.

\section{References}

1. C. Bazerman (1988), Shaping Written Knowledge: The Genre and Activity of the Experimental Article in Science, University of Wisconsin Press, Madison; C. Berkenkotter and T. Huckin (1995), Genre Knowledge in Disciplinary Communication: Cognition/Culture/ Power, Erlbaum, Hillsdale, NJ; C. Miller (1984), "Genre as social action," Quarterly Journal of Speech, 70, pp. 151-7.

2. A. Paré and G. Smart (1994), "Observing genres in action: Towards a research methodology," in A. Freedman and P. Medway (Eds.), Genre and the New Rhetoric, Taylor \& Francis, London, pp. 146-54.

3. C. Bazerman (1994), "Systems of genres and the enactment of social intentions," in A. Freedman and P. Medway (Eds.), Genre and the New Rhetoric, Taylor \& Francis, London, pp. 79-101; J. Yates and W. Orlikowski (2002), "Genre systems: Chromos and kairos in communicative interaction," in R. Coe, L. Lingard, and T. Teslenko (Eds.), The Rhetoric and Ideology of Genre, Hampton Press, Cresskill, NJ.

4. M. Cole and Y. Engeström (1993), "A culturalhistorical approach to distributed cognition," in G. Salomon (Ed.), Distributed Cognitions: Psychological and Educational Considerations, Cambridge University Press, Cambridge, UK, pp. 1-46.

\section{Graham Smart}

University of Wisconsin-Milwaukee, USA 